\title{
Co-authorships and gender bias in academia
}

\author{
Klarita Gërxhani, European University Institute ${ }^{1}$ \\ Nevena Kulic, University of Konstanz ${ }^{2}$ \\ Fabienne Liechti, University of Lausanne
}

April, 2020

\begin{abstract}
This article examines gender bias in the Italian academia, and whether this bias depends on one's collaborative work and its related conventions across academic disciplines. We carry out the research by relying on status characteristics theory, which is tested via a factorial survey experiment of 2,098 associate and full-time professors employed in Italian public universities in 2019. This is one of the few experiments of the hiring process in academia conducted on a nationally representative population of university professors. Our article focuses specifically on three academic disciplines: humanities, economics, and social sciences. The results indicate that female academics in Italy are penalized for co-authoring. They receive less favorable evaluations of their competence, but only when the evaluator is a male. This gender bias is most pronounced in economics, a discipline where conventions of coauthorship allow for more uncertainty on individual contributions to a joint publication. Overall, the results partially confirm our postulates based on status characteristics theory.
\end{abstract}

Keywords: Gender bias, academia, status characteristics theory, factorial survey experiment

\footnotetext{
${ }^{1}$ The order of the authors is alphabetical. All authors contributed equally to this article.

2 Corresponding author: Nevena Kulic, Cluster "Politics of Inequality", University of Konstanz, email: nevena.kulic@uni-konstanz.de
} 


\section{Introduction}

One of the major questions when studying gender inequality in academia is whether there is a systematic bias in the evaluation of women. Evaluation may relate to various aspects of academic activity, such as research, teaching, networks, etc. In particular, there are concerns about whether the same standards are applied when evaluating the quality of scientific production of women and men. Publications are considered a strong indication of one's quality in academia, and it has been theoretically argued and empirically shown that returns to co-authored research are different for women and men. For instance, male political scientists who collaborate at same rate as women, profit more from these collaborations. They produce, on average two publications more, so co-authorships tend to ultimately amplify gender differences in publications (Djupe et al., 2019). Moreover, women receive less professional recognition than men for their collaborative work, despite contributing equally or more (Abramo et al., 2013). The phenomenon of overlooked women's contributions is often termed the Matilda effect after the name of the scientist who first formulated it (Lincoln et al. 2012). In a recent empirical study, Sarsons et al. (2020) found that after controlling for quality of scientific work, women, in comparison to men, receive less credit when they co-author, and especially if they co-author with men.

The underlying argument of different returns across gender is that when evaluating one's publication record, the uncertainty of who contributed what is much higher with a co-authored publication than with a solo-authored publication. To better understand what happens in such high-uncertainty situations, status characteristics theory and its arguments about women's competence and their contribution to group work may prove to be valuable. This theory predicts that women will receive less credit than men for 
collaborative research as long as there are generally held beliefs that women in general, and female academics in specific, have lower competence than men (Correll et al. 2007, Ridgeway 2009). The limited empirical evidence (Sarsons et al. 2020) supports these expectations, but only for the field of economics and in the US context. Given that different academic disciplines operate based on different conventions (Waltman 2012), the question arises as to whether such discriminatory behavior can be generalized across academic fields and outside the US. After all, if co-authorships are indeed sending different signals for women than for men, this could help address preferential hiring and promotion patterns across gender in the academic world. This argument is particularly relevant today as the share of collaborative work in many disciplines, including social sciences, is increasing (Abramo et al., 2013).

Hence, the following questions underlie the research presented in this article. Does bias occur in the evaluation of equally productive men and women in academia, and what is the role of the composition of their co-authored work therein? Do conventions for co-authored work across disciplines influence the extent of biased evaluations? Which scientific discipline is more prone to biased evaluation of co-authored work?

The article addresses these questions, and by doing, so provides a test of status characteristics theory in academia, based on a factorial survey experiment (also known as vignette experiment). In such experiments, respondents are asked to evaluate fictional candidates based on their descriptions that vary on several characteristics (Aupurg an Hinz, 2015). Factorial survey experiments have been widely employed for studying hiring behaviour (Damelang and Abraham 2016; Di Stasio, 2014; Di Stasio and Gërxhani 2015; Liechti 2019; McDonald 2017). In contrast to observational 
data, studying hiring behaviour by experimental data has the advantage that the researchers can control for the information provided to participants and therefore limit potential bias due to unobservable characteristics. To our knowledge, this is one of the few experiments for hiring in academia based on a nationally representative population of university professors. Limited previous research has studied gender bias using observational and administrative data.

In the experiment, we focus on humanities, economics, and social sciences due to the more homogeneous nature of their evaluating criteria, which enables comparisons across these disciplines based on the same experiment. ${ }^{1}$ Our factorial survey experiment aims to mimic the decision-making process that is assumed to take place when hiring candidates for assistant professorships -with and without tenure- in the Italian academic setting. We chose to focus on this crucial moment in an academic career because that path is characterized by a notable lack of women in tenured or tenure track positions succeeding doctoral studies. This phenomenon is known as the 'leaky pipeline' (van Anders 2004). The vignette experiment was conducted in June 2019 among associate and full professors at public Italian universities. These participants were asked to assess two inter-related dimensions of the potential academic success of fictious candidates: (1) the probability that they would be shortlisted, and (2) their competence for the position. Capturing both dimensions enables a better understanding of the findings: the former dimension reflects potential behavioral action in the form of shortlisting, while the latter reflects the evaluator's beliefs about the candidate's competence. Moreover, it allows us to test status characteristics theory in academia with respect to two inter-related but distinct outcomes. 


\section{Status characteristics theory in academia}

According to status characteristics theory, discrimination occurs due to different performance expectations of men and women (Ridgeway and Krichelin-Katz 2013; Correll et al. 2006). This difference occurs because gender is used as a status characteristic, meaning that one category of a nominal distinction (i.e. men) is associated with greater competence, i.e., higher status, than the other category (i.e. women). If gender is a status characteristic, gender discrimination is driven by a cognitive bias that incorporates widely held cultural beliefs about the worthiness and competence of each gender (Correll 2006; Correll and Benard 2006). This cognitive bias becomes particularly salient in mixed-gender environments in which men's and women's levels of competence or commitment are ambiguous. An extension of status characteristics theory, known as the 'double standard approach', argues that even when competence is known and of the same level for men and women, those with a perceived lower status (i.e. women) will be evaluated based on stricter standards than those with a higher status (i.e. men) (Foschi 1989). "As a result, equal task performances are more likely to be judged as indicative of ability when performed by a higher status member of the group." (Correll and Ridgeway 2003:41).

Academic jobs are culturally considered a male occupation (Coate and Howson 2016; Witz 1990), substantiated by scant female representation at higher professorship levels. This is similar to what is seen in high level management positions (van den Brink et al. 2016; Reskin and Bielby 2005). Thereby, discriminatory behavior towards female academics may result from status beliefs concerning either their lesser ability, or their lower level of commitment, or could be due to stricter evaluation standards (Correll and Benard 2006; Ridgeway 2009). Having an academic career implies an expectation about the high level commitment needed to succeed in the 
profession (Van den Brink and Benschop 2012). This means that if there are cultural beliefs about women being expected to commit less than men, female academics may be evaluated by stricter standards, even when they are equally capable. Hence, we expect female academics to receive less favorable evaluations than their male colleagues at equal levels of merit, in terms of productivity (total number of single and co-authored articles)(H1).

Nevertheless, even if female and male academics produce commensurate academic output (e.g., quantity and quality of publications), uncertainty can arise when it is ambiguous who contributed what to that output. Given that academic research is often jointly conducted (e.g., joint publications), the exact contribution of each author is not observable. Status characteristics theory argues that when applied to collective tasks in particular (i.e., members of a group working on a collective goal like a joint publication), women's contributions are less valued than are men's (Correll and Ridgeway 2003; Correll 2006). Furthermore, the ambiguity of who did what in joint publications may vary, depending on the academic setting; different academic disciplines may operate based on different conventions and practices. For instance, regarding co-authored publications, economics applies the convention of typically listing the authors in alphabetical order (Kuld and O'Hagan 2018; Van Praag and Van Praag, 2008) without specifying the contribution of each individual author. Humanities and other branches of social sciences, on the other hand, rely on the declaration of each individual contribution (Waltman 2012). As a result, gender differentiated standards in the evaluation of men and women may be more marked, the higher the degree of ambiguity about men' and women's contribution to a collective task (Correll and Ridgeway 2003; Castilla 2008; Gorman and Kmec 2007; Foschi 1996). Considering these differences in degrees of ambiguity across disciplines, we expect that the less favorable evaluations for female academics will be particularly 
pronounced in disciplines with higher degrees of ambiguity regarding contributions to joint publications (H2).

\section{Case study: Entry-level hiring in Italy}

We test the above hypotheses by examining whether hiring decisions at the entry-level academic positions are gender biased. The case we focus on is the Italian academia. With 36 percent women in academia, Italy's figures are slightly above the EU-28 average ratio of 33 percent of female academics. According to the Italian Ministry of Education, University and Research (MIUR) (own elaboration of the 2018 administrative data), women account for 22.34 percent of full professorships (slightly below the 24 percent found in the EU; European Commission, 2018), while women's full professorships in social sciences and humanities is at 28 percent. Italy has recently been trying to modernize the academic system via reforms that have closely followed the Anglophone model of revising academic career progression. The reforms, that took place in 2012 ("Gelmini Law" (210/2010)), resulted in the establishment of tenure track and non-tenure track assistant professorships. The former group of professorships is based on the rule that after three years the employment continues into a promotion to associate professorship, dependent on the candidate having a positive evaluation and upon the receipt of national habilitation. We refer to these positions as tenure-track positions. The regulations for obtaining national habilitation set a clear standard for the number of publications that are needed for being eligible for a tenure post, and this threshold differs for each scientific discipline. The non-tenure track positions, instead, end after five years of employment (three years plus an additional two, conditional on a positive evaluation). Similar characteristics to such a model are found in other European countries such as Germany and the Netherlands. 
Yet, despite the formal reforms, the Italian academic system is known for the practice of clientelism and strong internal markets in academic positions, which set the entry barriers into the system much higher for outsiders and young scholars (Abramo et al. 2015). Informal practices of clientelism still dominate today, and they allow for gender discrimination among other issues; it is hard for a female academic to be successful (Checchi et al. 2019). Obtaining a position within Italian academia often depends on the right networking strategies and the structure and the character of individual connections (Marini and Maschitti 2018).

\section{Method}

Investigating hiring decisions in academia is not an easy task. First, because the availability of data is limited. Second, because even when available, the danger of social desirability and confounding factors would compromise the findings. That is why we rely on a factorial survey (vignette) experiment, which, as mentioned above, is an established method of studying employers' hiring strategies.

\section{Our factorial survey experiment in the Italian academia}

In our experiment, the participants (i.e. associate and full professors) were asked to evaluate descriptions of fictional candidates for assistant professorship in non-tenure and tenure-track positions. This was done to reflect the recent reforms in the Italian academia. In addition to introducing two types of tenure position, we varied the candidates' descriptions according to a number of other dimensions. First, those that best capture our main explanatory variables, namely candidate's gender and type of publication record (i.e. all co-authored vs. majority co-authored vs. majority singleauthored), as well as whether or not the candidate has been on parental leave ${ }^{2}$ (i.e. parent or not) and the status level of the candidate's ties (i.e. high vs. 
low). The latter two dimensions were included to account for well-known factors that might affect hiring decisions in academia (Abramo et al. 2015).

Table 1 below shows a detailed description of all the dimensions (see the appendix for an example of a vignette). The description of each dimension considers the above mentioned characteristics of the Italian academic system. These include the number of publications suitable for tenure and non-tenure track positions (which were fixed throughout all the vignettes), as well as the current regulation on parental (maternity/paternity) leave. The combination of all dimensions yields a vignette universe of 24 different combinations. Since the number of combinations is too large to be evaluated by every single participant, we grouped our vignette universe into four blocks of six vignettes each, relying on a d-optimal blocking that allows for the estimation of unconfounded main- and two-way-interaction effects (Kuhfeld 1994, Su and Steiner 2018). D-optimal blocking allows controlling for block effects in the empirical analysis and ensures that none of the dimensions are confounded with the blocks. Furthermore, to avoid socially desirable answers and to hide our interest in studying gender bias, we introduced gender as a betweenparticipant dimension, meaning that half of our participants saw only female candidates and the other half, only male candidates. Such a betweenparticipant design, in which the sensitive dimensions vary only between groups, is a common way to deal with social desirability biases in vignette studies (Walzenbach 2019).

Table 1: Dimensions of candidates' scientific profile included in the vignettes

\begin{tabular}{|c|c|}
\hline Dimension & Level \\
\hline $\begin{array}{l}\text { Gender } \\
\text { participants) }\end{array}$ & $\begin{array}{l}\text { Female } \\
\text { Male }\end{array}$ \\
\hline Type of position & Tenure track position \\
\hline
\end{tabular}




\begin{tabular}{|c|c|c|}
\hline & & Non-tenure track position \\
\hline $\begin{array}{l}\text { Type of } \\
\text { publication } \\
\text { record }\end{array}$ & $\begin{array}{l}\text { Tenure track } \\
\text { position }\end{array}$ & $\begin{array}{l}\text { Majority single authored ( } 7 \text { single vs. } 3 \text { co- } \\
\text { authored) } \\
\text { Majority co-authored ( } 7 \text { co-authored vs. } 3 \\
\text { single) } \\
\text { All co-authored }\end{array}$ \\
\hline & $\begin{array}{l}\text { Non-tenure } \\
\text { track position }\end{array}$ & $\begin{array}{l}\text { Majority solo authored ( } 4 \text { single vs. } 1 \text { co- } \\
\text { authored) } \\
\text { Majority co-authored ( } 4 \text { co-authored vs. } 1 \\
\text { single) } \\
\text { All co-authored }\end{array}$ \\
\hline Parental lea & & Yes/No parental leave interruption \\
\hline Status of tie & & $\begin{array}{l}\text { High: research collaborations with } \\
\text { influential scholars } \\
\text { Low: research collaborations with scholars } \\
\text { at the same academic level }\end{array}$ \\
\hline
\end{tabular}

\section{Notes:}

1. Gender was signalled by choosing typical Italian male and female names.

2. The number of total publications was adopted in relation to the position for which the candidate was applying, with a higher number of publications for tenured positions. The total number of publications was 10 for tenured track positions and 5 for non-tenured track positions.

Vignette blocks were randomly assigned to participants. Once respondents started participating in the survey, each of them was assigned to one block. In addition, the order of the vignette was randomized within one block to avoid order effects (Su and Steiner 2018). The vignettes were presented sequentially but the participants were able to go back and forth between the 
vignettes to avoid censoring (Auspurg and Hinz 2015). Each participant was asked to evaluate a set of six candidates on two dependent variables on a scale from 1 (worst evaluation) to 7 (best evaluation). The dependent variables were: (1) the likelihood that the participant would invite the candidate for a job interview, and (2) how well qualified the candidate was for the position.

After the vignettes, additional questions were asked, concerning, for instance, participants' sociodemographic characteristics, their departments, and specifically, their departments' hiring procedures.

\section{Data}

Our sample consists of a random subsample of Italian professors (associate and full professors) in humanities, economics, and social sciences (i.e., political science and sociology). The Ministry of Education, Universities and Research (MIUR) has compiled an official list of disciplines, which are divided into 14 major discipline areas amounting to more than 150 disciplines. To give an example, philosophy and history are grouped together in area 11, all forms of law are defined as area 12 , whereas mathematics, physics or chemistry are all in area 1 . More specifically, area 11, which we denote as 'humanities', includes history, geography, psychology, pedagogy and philosophy. Area 13 'economics' includes demography, economics and statistics. Area 14 'social sciences' includes social and political science as well as international relations. We restricted our sample to these three areas (i.e., areas 11, 13 and 14), as requirements for an academic career in Italy are similar across them. This allowed us to conduct the same vignette experiment across more than one discipline. Nevertheless, these areas differ regarding the representation of women at higher academic levels. According to our own calculations from the 2018 MIUR data, in humanities, 45.84 percent of the academics are on average female assistant- associate- and full-time professors, in comparison 
to 37 and 39 percent in economics and social sciences. Full time female professors account for 35 percent of total full-time professors in humanities, and 23 and 27 percent in economics and social sciences, respectively.

We obtained a list with all associate and full professors in Italy in April 2018 from the official database of MIUR. Out of 5,985 professors in areas 11,13 and 14 , we drew a random subsample of 2,262 individuals, stratified by rank and discipline of the professors. The email addresses of all professors in this subsample were collected manually. Of these, 164 email addresses were invalid and therefore our sample consists of 2,098 individuals. The vignettes were submitted to the participants via an online survey administered in Qualtrics $₫$ and participants were incentivized through the possibility of participating in a price draw for an iPad. After one week, a reminder was sent to those who had not responded. We obtained a response rate of 18.82 percent, which resulted in 395 respondents and 2,382 rated vignettes.

A common challenge when conducting surveys is that there might be a response bias: respondents may differ significantly from non-respondents, thus leading to biased results. Our data allows us to partially address this bias by comparing available characteristics for respondents and non-respondents. Since we know the gender, rank, and discipline area of respondents and nonrespondents, we compared the two groups with respect to these variables. The characteristics of respondents and non-respondents are given in Table A1, in the appendix. We note that women are slightly over-represented among respondents, accounting for 41.24 percent of the total, versus 36.18 percent among non-respondents. Also, associate professors and professors from social sciences were more likely to participate in the survey.

\section{Model}

Since the vignettes are nested within respondents, we estimate linear multilevel models to investigate the effects of the vignette dimensions on the two 
dependent variables. A multi-level framework is needed because the experiment includes two types of independent variables, one at the level of the respondent and another, at the vignette level. The dependent variable is on a scale from 1-7, therefore linear models are employed. The major independent variables of interest are the gender of the fictional candidates and the type of publication record, namely, whether the candidate has only co-authored publications, has a majority of co-authored publications, or a majority of single-authored publications. The models additionally control for whether the candidate has taken parental leave, the status of candidates' ties within their professional networks, and the type of tenure position, as these are characteristics that may play an important role in the hiring process.

Finally, the models control for respondents' characteristics such as gender, the discipline areas (humanities, economics or social sciences), rank (associate or full professor), and the characteristics of their departments (departmental fixed effects). Because the distribution of the dependent variables is somewhat skewed to the left, ordered multi-level random intercept logistic regression was used as a robustness check, which confirms the results of the linear multi-level random intercept regression. The models were run on the whole sample and on two subsamples. One subsample is based on respondents' gender, as there might be differences in the evaluation of men and women depending on the gender of the evaluator (Bagues et al., 2017; Sarsons et al. 2020). The other subsample is based on the discipline areas in which respondents work, which allows us to test our hypotheses across academic fields.

\section{Results}

\section{Descriptives}

A first examination of the dependent variables, displayed in Table 2 below, shows that the mean of being shortlisted is relatively high, namely 5.75 
percent for the whole sample. There is some difference in evaluation across respondents' gender, but it is not statistically significant. Overall, the average evaluation for competence is lower than evaluations for the possibility of being shortlisted, namely 5.25 vs. 5.75 , but again without any differences across respondents' gender. There is, however, substantial difference in ranking across discipline areas, with the lowest competence evaluations and the lowest probability in shortlisting occurring in the humanities, and the highest, in economics. The difference is statistically significant, which indicates some variation in the evaluation of the candidates across different academic fields ( $p$-value $=0.00$ for both outcomes).

Table 2: Mean and standard deviation of dependent variables, by participants' discipline area and gender

\begin{tabular}{llllll}
\hline & \multicolumn{2}{l}{ Shortliste } \\
& $\mathrm{d}$ & \multicolumn{2}{l}{ Qualified } \\
& Mea & \multicolumn{3}{c}{ Mea } \\
& $\mathrm{n}$ & $\mathrm{Sd}$ & $\mathrm{n}$ & $\mathrm{Sd}$ \\
\hline & 5.7 & 1.3 & 5.2 & 1.3 \\
All sample & 5 & 5 & 5 & 7 \\
& 5.8 & 1.2 & 5.2 & 1.3 \\
Female respondents & 0 & 9 & 5 & 3 \\
& 5.7 & 1.3 & 5.2 & 1.3 \\
Male respondents & 2 & 9 & 5 & 9 \\
Area 11 'Humanities' & & & & \\
(history, geography, psychology, pedagogy and & 5.5 & 1.4 & 5.0 & 1.4 \\
philosophy) & 7 & 5 & 7 & 2 \\
Area 13 'Economics' & 5.8 & 1.3 & 5.4 & 1.3 \\
(demography, economics and statistics) & 9 & 8 & 2 & 8
\end{tabular}


Area 14 'Social Sciences'

(social and political science, and international relations)

5.7

$5.2 \quad 1.2$

$\begin{array}{llll}6 & 1.2 & 3 & 9\end{array}$

Male and female candidates receive similar marks from those who evaluate them for both shortlisting and competence (analysis available upon request). In other words, there seems to be no gender bias in the evaluation of candidates, when the characteristics of the candidates' profiles are not controlled for. Also, the evaluation is not dependent on the gender of the evaluator.

\section{Stricter standards for female academics?}

Table 3 shows the results of multi-level linear regressions - for the overall sample and for the subsample according to respondents' gender - on both dependent variables: probability of being shortlisted and judged to be qualified. We first discuss the results for the whole sample (columns one and two of the table). They indicate that the type of publication record does not seem to affect either of the dependent variables differently for male and female candidates. In other words, the interaction terms, between the candidate's gender and whether the publications are all co-authored, majority co-authored or majority single authored, are not significant. Therefore, based on the whole sample of respondents and controlling for all other characteristics, we do not find support for our first hypothesis, that female academics receive less favorable evaluations than their male colleagues at equal level of merit. Put differently, there seem to be no stricter standards for assessing female academics in Italy.

Some of the control variables have a significant influence on the outcomes. Namely, those applying for a tenure-track position are more likely to be 
shortlisted and considered qualified than those applying for a non-tenure track position; candidates who collaborate with scholars of similar academic level, i.e., those who have low status ties, are evaluated more negatively in both shortlisting and competence than candidates who collaborate with influential scholars, i.e., those who have high status ties. These findings are in line with the literature, given that the status of the position one applies for as well as the status of his or her ties signal a higher ranking of that candidate (e.g., Lin et al. 1981). Taking parental leave is insignificant in the model with shortlisting as a dependent variable, but signalled a higher competence, although of a moderate effect $(0.085$, significant at 1 percent level). In other words, equally productive candidates are considered more competent if they have reached their current academic level in addition to caring for children. However, this result might also stem from a select sample of respondents who have participated in the experiment. The inclusion of the second level variables such as discipline areas, respondent's gender and departmental fixed effects only marginally changes the results. Moreover, additional regressions were run, controlling for respondents' total number of publications, number of single publications, and the number of their co-authors. The results remain largely unchanged, but the sample size decreases by 200 observations. The only significant and positive effect found is for the number of respondents' coauthors, which positively affects the evaluation of vignettes; the more respondents co-author, the more generous they are when evaluating the vignette profiles. These additional results are available upon request.

Table 3: Multi-level linear regressions with random intercept: Likelihood of being shortlisted and of being judged qualified (whole sample and subsample according to respondents' gender) 


\begin{tabular}{|c|c|c|c|c|c|c|}
\hline VARIABLES & $\begin{array}{c}\text { Being } \\
\text { shortliste } \\
\text { d }\end{array}$ & $\begin{array}{c}\text { Being } \\
\text { qualified }\end{array}$ & $\begin{array}{c}\text { Being } \\
\text { shortliste } \\
\text { d }\end{array}$ & $\begin{array}{c}\text { Being } \\
\text { qualified }\end{array}$ & $\begin{array}{c}\text { Being } \\
\text { shortliste } \\
\text { d }\end{array}$ & $\begin{array}{c}\text { Being } \\
\text { qualified }\end{array}$ \\
\hline \multicolumn{7}{|l|}{ Vignette dimensions } \\
\hline & & $0.257 * *$ & & $0.170 * *$ & & $0.377 * *$ \\
\hline \multirow[t]{2}{*}{ Tenure track position } & $\begin{array}{c}0.268 * * * \\
(0.034)\end{array}$ & $\begin{array}{c}* \\
(0.039)\end{array}$ & $\begin{array}{c}0.216 * * * \\
(0.045)\end{array}$ & $\begin{array}{c}* \\
(0.049)\end{array}$ & $\begin{array}{c}0.337 * * * \\
(0.050)\end{array}$ & $\begin{array}{c}* \\
(0.062)\end{array}$ \\
\hline & & & & & & - \\
\hline \multirow[t]{2}{*}{ Female candidate } & $\begin{array}{l}-0.180 \\
(0.147)\end{array}$ & $\begin{array}{l}-0.090 \\
(0.144)\end{array}$ & $\begin{array}{l}-0.139 \\
(0.197)\end{array}$ & $\begin{array}{l}-0.041 \\
(0.186)\end{array}$ & $\begin{array}{l}-0.308 \\
(0.224)\end{array}$ & $\begin{array}{c}0.464 * * \\
(0.214)\end{array}$ \\
\hline & & - & & - & & - \\
\hline Co-authored publications & - & $0.342 * *$ & & $0.252 * *$ & & $0.477 * *$ \\
\hline \multirow[t]{2}{*}{ only } & $\begin{array}{c}0.200 * * * \\
(0.057)\end{array}$ & $\begin{array}{c}* \\
(0.066)\end{array}$ & $\begin{array}{c}-0.191 * * \\
(0.075)\end{array}$ & $\begin{array}{c}* \\
(0.082)\end{array}$ & $\begin{array}{c}-0.214 * * \\
(0.087)\end{array}$ & $\begin{array}{c}* \\
(0.108)\end{array}$ \\
\hline & & $0.381 * *$ & & $0.467 * *$ & & \\
\hline Majority single authored & $\begin{array}{c}0.324 * * * \\
(0.057)\end{array}$ & $\begin{array}{c}* \\
(0.066)\end{array}$ & $\begin{array}{c}0.373 * * * \\
(0.075)\end{array}$ & $\begin{array}{c}* \\
(0.082) \\
-\end{array}$ & $\begin{array}{c}0.251 * * * \\
(0.087)\end{array}$ & $\begin{array}{l}0.251 * * \\
(0.108)\end{array}$ \\
\hline Female candidate\#co- & & & & $0.319 * *$ & & \\
\hline authored only & $\begin{array}{l}-0.040 \\
(0.082)\end{array}$ & $\begin{array}{l}-0.098 \\
(0.095)\end{array}$ & $\begin{array}{l}-0.117 \\
(0.111)\end{array}$ & $\begin{array}{c}* \\
-0.121\end{array}$ & $\begin{array}{c}0.061 \\
(0.123)\end{array}$ & $\begin{array}{c}0.200 \\
(0.152)\end{array}$ \\
\hline \multicolumn{7}{|l|}{ Female candidate\#majority } \\
\hline single authored & $\begin{array}{l}-0.012 \\
(0.083)\end{array}$ & $\begin{array}{l}-0.004 \\
(0.095)\end{array}$ & $\begin{array}{l}-0.065 \\
(0.111)\end{array}$ & $\begin{array}{l}-0.120 \\
(0.121)\end{array}$ & $\begin{array}{c}0.067 \\
(0.123)\end{array}$ & $\begin{array}{c}0.164 \\
(0.152)\end{array}$ \\
\hline \multirow[t]{2}{*}{ Parental leave } & $\begin{array}{c}0.022 \\
(0.034)\end{array}$ & $\begin{array}{c}0.085 * * \\
(0.039)\end{array}$ & $\begin{array}{l}-0.010 \\
(0.045)\end{array}$ & $\begin{array}{c}0.098 * * \\
(0.049)\end{array}$ & $\begin{array}{c}0.064 \\
(0.050)\end{array}$ & $\begin{array}{c}0.068 \\
(0.062)\end{array}$ \\
\hline & & $\begin{array}{c}- \\
0.104 * *\end{array}$ & & $\begin{array}{c}- \\
0.131 * *\end{array}$ & & \\
\hline Low status ties & $\begin{array}{c}-0.074 * * \\
(0.034)\end{array}$ & $\begin{array}{c}* \\
(0.039)\end{array}$ & $\begin{array}{c}-0.090 * * \\
(0.045)\end{array}$ & $\begin{array}{c}* \\
(0.049)\end{array}$ & $\begin{array}{l}-0.052 \\
(0.050)\end{array}$ & $\begin{array}{l}-0.065 \\
(0.062)\end{array}$ \\
\hline \multicolumn{7}{|l|}{$\begin{array}{l}\text { Respondents' } \\
\text { characteristics }\end{array}$} \\
\hline Area 13 'Economics' & $\begin{array}{l}-0.130 \\
(0.317)\end{array}$ & $\begin{array}{l}-0.193 \\
(0.303)\end{array}$ & $\begin{array}{l}-0.059 \\
(0.497)\end{array}$ & $\begin{array}{l}-0.186 \\
(0.459)\end{array}$ & $\begin{array}{l}-0.478 \\
(0.386)\end{array}$ & $\begin{array}{c}-0.485 \\
(0.355) \\
-\end{array}$ \\
\hline Area 14 'Social science' & $\begin{array}{l}-0.255 \\
(0.232)\end{array}$ & $\begin{array}{l}-0.246 \\
(0.222)\end{array}$ & $\begin{array}{c}0.076 \\
(0.277)\end{array}$ & $\begin{array}{c}0.152 \\
(0.256)\end{array}$ & $\begin{array}{l}-0.638 \\
(0.392)\end{array}$ & $\begin{array}{c}0.893 * * \\
(0.360)\end{array}$ \\
\hline Full professor & -0.076 & -0.149 & 0.167 & 0.198 & 0.144 & -0.026 \\
\hline
\end{tabular}



(0.152)
(0.145)
$(0.221)$
$(0.204)$
(0.217)

(0.200)

Male respondent

$(0.141)$

Departments

$\mathrm{X}$

(0.135)

$\mathrm{X}$

1.678

1.678

967

967

711

711

Number of groups

(respondents)

289

289

167

167

122

122

Standard errors in

parentheses

Notes: $(\bullet)$ Reference categories are: Non-tenure track positions, male candidates, majority co-authored, has not taken parental leave, high status ties, Area 11 'Humanities', associate professor, female respondent. *** $\mathrm{p}<0.01, * * \mathrm{p}<0.05, * \mathrm{p}<0.1$

Yet, the full sample may hide heterogeneous patterns between two subgroups: male and female respondents. As shown in columns three to seven of Table 3, male and female respondents do not differ in their evaluation of a candidate's probability of being shortlisted, irrespective of the candidate's publication record. When it comes to evaluating how qualified a candidate is, however, male respondents judge female candidates who have only coauthored publications less qualified than the equivalent male candidates. More specifically, the interaction between being a female candidate and having only co-authored publications is associated with a decrease in the evaluation of that candidate's competence by -0.316 (statistically significant at 1 percent level) on a scale of 1-7. In other words, male respondents do seem to hold stricter standards for female academics, net of all other characteristics. This is not the case for the subsample of female respondents. The difference between male and female respondents is statistically significant and the results are generalizable outside of the current sample. 
These effects remain unchanged after including the control variables. While the direct significant effect of some of the control variables, like tenure track position, is similar to that found for the whole sample, the effect of other controls differs across the overall sample and the two subsamples. For instance, only male respondents evaluate candidates with low status ties more negatively than candidates with high status ties, in both shortlisting and competence. Also, only male respondents evaluate candidates who are parents as more qualified than those who are not. Female respondents, on the other hand, judge a candidate's competence to be lower when she is a female whose majority of publications is co-authored and when the discipline area concerned is social sciences (significant at 5 percent level).

\section{Variation in evaluation standards across disciplines?}

To test our second hypothesis, which predicts less favorable evaluations for female academics in disciplines with higher degrees of ambiguity regarding contributions to joint publications, we ran further analyses, as reported in Table 4 below. We perform the analyses for the selected three areas separately: area 11 'humanities', area 13 'economics', and area 14 'social sciences'. As discussed above, although applying comparable evaluating criteria, these areas differ in their conventions of how co-authors are listed in a joint publication. This varies from a listing in alphabetical order such as that practiced in economics to a based-on-individual-contribution listing, which is more common in humanities and social sciences. As a result, the degree of ambiguity in who did what in a joint publication is higher in economics compared to humanities and social sciences.

Table 4 reports the results for different discipline areas for the sample of male respondents only. The results for female respondents for the three discipline areas do not differ qualitatively from those reported above with respect to the whole sample of female respondents (available upon request). Male 
respondents do not differentiate between male and female candidates when evaluating their likelihood to be shortlisted, irrespective of the discipline area they are from. It is again when male respondents evaluate whether the candidate is qualified that we observe a stricter standard towards females, but only for area 13, economics. Male economists seem to penalize female candidates who co-author by -0.512 on a 7 point scale (significant at 1 percent) compared to males who co-author. Since economics is the discipline with higher degrees of ambiguity regarding contributions to joint publications, this finding supports our second hypothesis. However, only partially, because it only holds for male economists. As for the control variables, candidates applying for a tenure-track position are more likely to be shortlisted and considered qualified in humanities and social sciences. Having a low status tie negatively affects the likelihood of being shortlisted and of being considered qualified in social sciences only. Other controls reveal a similar direction as in the previous models but show insignificant effects.

Table 4: Multi-level linear regressions with random intercept. Likelihood of being shortlisted and of being judged qualified (sample of male respondents across disciplines)

\begin{tabular}{|c|c|c|c|c|c|c|}
\hline \multirow[b]{2}{*}{ VARIABLES } & \multicolumn{3}{|c|}{ Being shortlisted } & \multicolumn{3}{|c|}{ Being qualified } \\
\hline & Human & Econ & Social & Human & Econ & Social \\
\hline \multirow[t]{2}{*}{ Tenure-track position } & $\begin{array}{c}0.403^{* *} \\
*\end{array}$ & -0.055 & $\begin{array}{c}0.325^{* *} \\
*\end{array}$ & $\begin{array}{c}0.367^{* *} \\
*\end{array}$ & -0.009 & $0.197 * *$ \\
\hline & -0.087 & -0.076 & -0.07 & -0.088 & -0.08 & -0.082 \\
\hline \multirow[t]{2}{*}{ Female candidate } & $0.809 * *$ & -0.283 & -0.379 & 0.227 & 0.016 & -0.377 \\
\hline & -0.327 & -0.363 & -0.248 & -0.37 & -0.294 & -0.267 \\
\hline \multirow[t]{2}{*}{ Co-authored publications only } & -0.179 & -0.121 & $-0.263 * *$ & -0.108 & -0.185 & $-0.403 * * *$ \\
\hline & -0.146 & -0.126 & -0.115 & -0.148 & -0.133 & -0.135 \\
\hline Majority single authored & $\begin{array}{c}0.449 * * \\
*\end{array}$ & $0.270 * *$ & $\begin{array}{c}0.428^{* *} \\
*\end{array}$ & $\begin{array}{c}0.518^{* *} \\
*\end{array}$ & $0.422 * * *$ & $0.487 * * *$ \\
\hline
\end{tabular}




\begin{tabular}{lcccccc} 
& -0.146 & -0.126 & -0.116 & -0.148 & -0.133 & -0.136 \\
$\begin{array}{lccccc}\text { Female candidate\#co-authored } \\
\text { only }\end{array}$ & 0.021 & -0.2 & -0.132 & -0.287 & $-0.512 * * *$ & -0.178 \\
& -0.212 & -0.186 & -0.172 & -0.215 & -0.197 & -0.202 \\
Female candidate\#majority & & & & & & \\
single authored & 0.051 & 0.018 & -0.233 & -0.018 & -0.143 & -0.189 \\
& -0.212 & -0.186 & -0.172 & -0.215 & -0.197 & -0.202 \\
Parental leave & -0.022 & -0.002 & -0.015 & 0.047 & 0.115 & 0.115 \\
& -0.087 & -0.076 & -0.07 & -0.088 & -0.08 & -0.082 \\
Low status ties & -0.049 & -0.027 & $-0.167 * *$ & -0.026 & -0.098 & $-0.225 * * *$ \\
& -0.087 & -0.076 & -0.07 & -0.088 & -0.08 & -0.082 \\
Second level controls & $\mathrm{X}$ & $\mathrm{X}$ & $\mathrm{X}$ & $\mathrm{X}$ & $\mathrm{X}$ & $\mathrm{X}$ \\
$\begin{array}{l}\text { Observations } \\
\text { Number of groups }\end{array}$ & 245 & 328 & 394 & 245 & 328 & 394 \\
(respondents) & 43 & 56 & 68 & 43 & 56 & 68 \\
\hline
\end{tabular}

Notes: Reference categories as above. Second level controls include ranks and department fixed effects. $* * * \mathrm{p}<0.01, * * \mathrm{p}<0.05, * \mathrm{p}<0.1$

\section{Conclusion}

Given the balanced share of women and men at the doctoral level, the paucity of women represented in higher stages of academic career (European Commission 2015) can be considered dramatic. The mechanisms underlying this imbalance can be supply or demand driven and the two are often difficult to disentangle. This article aims to address this difficulty by isolating and uncovering some of the demand-side mechanisms and thus focuses on the gatekeeper effect underlying unequal gender representation in academia. It does so by examining whether evaluations of competence and hiring propensities at the entry level academic positions are gender biased, which would influence underrepresentation of women in later stages of the academic career.

In line with status characteristics theory, we predicted that female academics would be evaluated less favorably for their collaborative work in comparison to male academics, and particularly in disciplines with higher degrees of 
ambiguity regarding contributions to joint publications. This was tested by means of a factorial survey experiment among Italian professors in humanities, economics and social sciences.

Our results show that female academics in Italy are indeed penalized for coauthoring. They receive less favorable evaluations of their competence, but only when the evaluator (an associate or full professor) is a male. This gender bias is most pronounced in economics, a discipline whose conventions of coauthorships allow for more uncertainty on individual contributions to a joint publication. These findings complement recent observational evidence which focuses primarily on the field of economics in the US (Sarsons et al. 2020). By comparing various academic disciplines that operate based on different conventions, and in a different context, our experimental study contributes to a broader question of the 'boundaries' of gender bias. It seems that gendered beliefs and conventions within disciplines matter the most and thus transcend the boundaries of national contexts. The larger implication of these findings is that, when it comes to collaborative work, which is ever increasing in academia, women's contribution is underestimated, confirming some of the postulates of the status characteristic theory. It is, however, important to emphasize that, contrary to the empirical evidence that finds that both sexes are likely to show bias against women when hiring in academia (Moss-Racusin et al., 2012; Bagues et al., 2017), our study underlines the presence of male bias in the Italian academic context. If this result can be confirmed for other academic contexts, it calls for raising awareness to counter such biases and to reinforce equal representation of men and women in academic organizations.

Interestingly, we do not observe any gender bias in the evaluators' likelihood of inviting a candidate for a job interview (i.e. shortlisting). Women are 
shortlisted as often as men, irrespective of the gender of the evaluator and of the discipline. On the one hand it can be expected that if a female candidate is judged competent, she will also more likely be shortlisted. On the other hand, a female candidate may be judged less competent and still be shortlisted, if there are internal and external pressures to increase gender equality. Such pressures are more and more present worldwide, but also within the Italian academia (MIUR, 2018). Moreover, being invited for an interview is only the first step to hiring, and inviting a 'less competent' female candidate could signal compliance with the pressures while allowing for her exclusion in the later stages of hiring process.

A potential limitation of our study is that even though current evidence shows that vignette studies are able to capture a real life behavior (Hainmueller et al. 2015), participants in factorial surveys know that their answers have no real consequences and that they might still act differently in real life situations. Furthermore, by addressing the social desirability bias with a split-sample design (respondents only saw one gender, either male or female candidates), we were not able to rely on within respondent information to test how a single respondent evaluated different genders. This way we traded within respondent variability for lower social desirability bias. Also, our vignettes include selected variables of theoretical interest and could not fully cover all relevant variables of an evaluation and hiring process. Finally, our experiment relies on decisions of single participants and therefore underplays the importance of group interactions between committee members, which can also drive the dynamics in evaluation and hiring. 


\section{Literature}

Abramo, G., D'Angelo, C.A., Rosati, F. (2015) 'The Determinants of Academic Career Advancement: Evidence from Italy', Science and Public Policy 42(6): 761-774.

Abramo, G., D'Angelo, C. A., \& Murgia, G. (2013). Gender differences in research collaboration. Journal of Informetrics, 7(4), 811-822.

Auspurg, K., \& Hinz, T. (2015). Factorial Survey Experiments. Los Angeles: SAGE.

Bagues, M., Sylos-Labini, M., \& Zinovyeva, N. (2017). Does the gender composition of scientific committees matter?. American Economic Review, 107(4), 1207-38.

Castilla, E. J. (2008) 'Gender, Race, and Meritocracy in Organizational Careers', American Journal of Sociology, 113 (6): 1479-1526.

Checchi, D., Cicognani, S., \& Kulic, N. (2019) 'Gender quotas or girls' networks? Towards an understanding of recruitment in the research profession in Italy', Work, employment and society.

Coate, K., \& Howson, C. K. (2016). Indicators of esteem: Gender and prestige in academic work. British Journal of Sociology of Education, 37(4), 567585.

Correll S.J., Benard, S., and Paik, I. (2007) 'Getting a job: Is there a motherhood penalty?', American Journal of Sociology, 112(5), 1297-1338. 
Correll, S. J. and Ridgeway, C. L. (2003) 'Expectation States Theory'. In Delamater, J. (ed) Handbook of Social Psychology, New York: Kluwer Academic/Plenum Publishers, pp. 29-51.

Di Stasio, V. (2014). Education as a Signal of trainability: results from a vignette study with Italian employers. European Sociological Review, $30(6), 796-809$.

Di Stasio, V. and Gërxhani, K. (2015). Employers' social contacts and their hiring behavior in a factorial survey. Social Science Research, 51, 93-107.

Djupe, P. A., Smith, A. E., \& Sokhey, A. E. (2019). Explaining Gender in the Journals: How Submission Practices Affect Publication Patterns in Political Science. PS: Political Science \& Politics, 52(1), 71-77.

European Commission (2018) She Figures 2018. Gender in Research and Innovation. Luxembourg: Publications Office of the European Union.

Foschi, M. (1996) 'Double Standards in the Evaluation of Men and Women', Social Psychology Quarterly, 59(3): 237-254.

Gorman, E. H. and Kmec, J. A. (2007) 'We (Have to) Try Harder: Gender and Required Work Effort in Britain and the United States', Gender and Society, 21 (6): 828-856.

Hainmueller, J., Hangartner, D., \& Yamamoto, T. (2015). Validating vignette and conjoint survey exeriments against real-world behaviour. Proceedings of the National Academy of Science of the United States of America, 112(8), 2395-2400. 
Kuhfeld, W. F., Tobias, R. D., Garratt, M., \& Tobias, D. (1994). Efficient Experimental Design Applications with Marketing Research Applications. Journal of Marketing Research, 31(4), 545-557.

Kuld, L., \& O'Hagan, J. (2018). Rise of multi-authored papers in economics: Demise of the 'lone star'and why?. Scientometrics, 114(3), 1207-1225.

Liechti, F. (2019). Connecting Employers and Workers: Can Recommendations from the Public Employment Service Act as a Substitute for Social Contacts? Work, Employment and Society, online first. https://doi.org/10.1177/0950017019836888

Lin, N., Ensel, W. M and Vaughn, J. C. (1981) 'Social Resources and Strength of Ties: Structural Factors in Occupational Status Attainment', American Sociological Review 46 (4): 393-405.

Lincoln, A. E., Pincus, S., Koster, J. B., \& Leboy, P. S. (2012). The Matilda Effect in science: Awards and prizes in the US, 1990s and 2000s. Social studies of science, 42(2), 307-320.

Marini, G., \& Meschitti, V. (2018). The trench warfare of gender discrimination: evidence from

academic promotions to full professor in Italy. Scientometrics, 115(2), 989-1006.

Reskin, B. F., \& Bielby, D. D. (2005). A sociological perspective on gender and career outcomes. Journal of Economic Perspectives, 19(1), 71-86.

McDonald, P. (2017). Improving our Understanding of Employer Decisionmaking Thanks to Factorial Survey Analysis. LIVES Working Paper,75, 138. http://dx.doi.org/10.12682/lives.2296-1658.2017.61 
Miur, 2018. Indicazioni per azioni positive del miur sui temi di genere nell'università e nella ricerca, accessed 03/04/2020.

Moss-Racusin, C. A., Dovidio, J. F., Brescoll, V. L., Graham, M. J., \& Handelsman, J. (2012). Science faculty's subtle gender biases favor male students. Proceedings of the national academy of sciences, 109(41), 16474-16479.

Ridgeway, C. L. (2011). Framed by gender: How gender inequality persists in the modern world. Oxford University Press.

Ridgeway C. L. (2009) 'Framed before we know it: How gender shapes social relations', Gender \& Society, 23(2): 145-160.

Ridgeway, C. L. and Kricheli-Katz, T. (2013) 'Intersecting cultural beliefs in social relations: Gender, race, and class binds and freedoms', Gender \& Society, 27(3): 294-318.

Ridgeway, C. and Correll, S. J. (2004) 'Motherhood as a Status Characteristics', Journal of Social Issues, 60(4): 683-700.

Sarsons, H., Gërxhani, K., E. Reuben and A. Schram (conditionally forthcoming). Gender Differences in Recognition for Group Work. Journal of Political Economy.

Su, D. \& Steiner P. (2018). An Evaluation of Experimental Designs for Constructing Vignette Sets in Factorial Surveys. Sociological Methods \& Research. Online First. https://doi.org/10.1177/0049124117746427

van den Brink, M., Holgersson, C., Linghag, S., \& Deé, S. (2016). Inflating and down playing 
strengths and weaknesses-Practicing gender in the evaluation of potential managers and partners. Scandinavian Journal of Management, $32(1), 20-32$.

Van Praag, C. M., \& Van Praag, B. M. (2008). The benefits of being economics professor A (rather than Z). Economica, 75(300), 782-796.

Van den Brink, M., \& Benschop, Y. (2012). Gender practices in the construction of academic excellence: Sheep with five legs. Organization, 19(4), 507-524.

Waltman, L. (2012). An empirical analysis of the use of alphabetical authorship in scientific publishing. Journal of Informetrics, 6(4), 700-711. 


\section{Appendix}

Table A1: Respondents' and Non-Respondents' characteristics

\begin{tabular}{|c|c|c|}
\hline Variable & Respondents & $\begin{array}{l}\text { Non- } \\
\text { Respondents }\end{array}$ \\
\hline \multicolumn{3}{|l|}{ Gender } \\
\hline $\begin{array}{l}\text { Female } \\
\text { Male }\end{array}$ & $\begin{array}{l}41.24 \\
54.30\end{array}$ & $\begin{array}{l}36.18 \\
63.82\end{array}$ \\
\hline \multicolumn{3}{|l|}{ Type of Rank } \\
\hline $\begin{array}{l}\text { Full time Professor: } \\
\text { Associate Professor: }\end{array}$ & $\begin{array}{l}30.75 \\
69.25\end{array}$ & $\begin{array}{l}36.29 \\
63.71\end{array}$ \\
\hline \multicolumn{3}{|l|}{ Discipline } \\
\hline Economics: & 32.30 & \\
\hline & & \\
\hline Humanities: & 26.36 & 32.98 \\
\hline Age & $\begin{array}{l}\text { Mean:54.99 } \\
\text { Sde: } 8.57 \\
\text { Min: } 30 \\
\text { Max: } 72\end{array}$ & \\
\hline $\begin{array}{l}\text { Length of academic } \\
\text { career }\end{array}$ & $\begin{array}{l}\text { Mean: } 26.91 \\
\text { Sde: } 8.60\end{array}$ & \\
\hline
\end{tabular}




\begin{tabular}{|c|c|}
\hline $\begin{array}{l}\text { (number of years in } \\
\text { academia) }\end{array}$ & $\begin{array}{l}\text { Min: } 1 \\
\text { Max:49 }\end{array}$ \\
\hline $\begin{array}{l}\text { Length of employment } \\
\text { within the department } \\
\text { (number of years) }\end{array}$ & $\begin{array}{l}\text { Mean: } 15.02 \\
\text { Sde: } 8.98 \\
\text { Min: } 0.5 \\
\text { Max: } 46\end{array}$ \\
\hline Number of publications & $\begin{array}{l}\text { Mean: } 66.53 \\
\text { Sde: } 28.10 \\
\text { Min: } 0 \\
\text { Max: } 250\end{array}$ \\
\hline $\begin{array}{l}\text { Share of female } \\
\text { professors at the } \\
\text { department }\end{array}$ & $\begin{array}{l}\text { Mean: } 7.06 \% \\
\text { Sde: } 3.37 \\
\text { Min: } 3 \% \\
\text { Max: } 18 \%\end{array}$ \\
\hline
\end{tabular}

Table A4: Vignette set-up

An example of a vignette (dimensions varied are indicated in italics)

Introductory text:

Vignette example:

There is an opening for a tenure track position of an assistant professorship. Giorgia Bianchi has a PhD from an Italian university and 6 years of Postdoc experience. She has obtained national grants for conducting her research, which has resulted in 10 peer-reviewed publications: 7 single authored and 3 
co-authored. Moreover, she has established research collaborations with scholars of similar academic level and has accumulated sufficient teaching experience at the Bachelor and Master levels.

Please rate the candidate on a scale from 0-7

a) How likely it is that you would invite the candidate for a job interview

b) How well the candidate is qualified to the position

\footnotetext{
${ }^{1}$ Note that the differences on such criteria between humanities, economic and social sciences and the rest of the disciplines (such as Stem, Technical, Life sciences) is quite large, for instance regarding the propensity of publication, publication standards, or coauthorships. Such differences would not allow for a proper comparison based on the same experiment.

${ }^{2}$ Being on parental leave refers to being on (mandatory) maternity or paternity leave of five months.
} 